\title{
Epidemiological Surveillance of Eye Disease and People Awareness in the Abruzzo Region, Italy
}

\author{
Leonardo Mastropasqua ${ }^{1}$, Rossella D'Aloisio ${ }^{1, *(\mathbb{D}, \text { Alessandra Mastrocola }}{ }^{1}$, Fabiana Perna ${ }^{1,2}{ }^{\text {, Luca Cerino }}{ }^{1}$, \\ Loredana Cerbara $^{3}{ }^{-0}$, Filippo Cruciani ${ }^{2}$ and Lisa Toto ${ }^{1}$ (I) \\ 1 Ophthalmology Clinic, Department of Medicine and Science of Ageing, \\ University G. D’Annunzio Chieti-Pescara, 66100 Chieti, Italy; mastropa@unich.it (L.M.); \\ studiomastrocola@gmail.com (A.M.); f.perna@iapb.it (F.P.); \\ lucacerino92@gmail.com (L.C.); 1.toto@unich.it (L.T.) \\ 2 Italian National Centre of Services and Research for the Prevention of Blindness and Rehabilitation of the \\ Visually Impaired-WHOCC, IAPB Italy Onlus-FPG IRCCS, 00185 Roma, Italy; filippo.cruciani@uniroma1.it \\ 3 Institute for Research on Population and Social Policies, Italian National Research Council (CNR-IRPPS), \\ 00185 Rome, Italy; loredana.cerbara@irpps.cnr.it \\ * Correspondence: ross.daloisio@gmail.com
}

\section{check for}

updates

Citation: Mastropasqua, L.;

D'Aloisio, R.; Mastrocola, A.; Perna,

F.; Cerino, L.; Cerbara, L.; Cruciani, F.;

Toto, L. Epidemiological Surveillance of Eye Disease and People Awareness in the Abruzzo Region, Italy. Medicina 2021, 57, 978. https://doi.org/

10.3390/medicina57090978

Academic Editor: Jack V. Greiner

Received: 15 July 2021

Accepted: 13 September 2021

Published: 17 September 2021

Publisher's Note: MDPI stays neutral with regard to jurisdictional claims in published maps and institutional affiliations.

Copyright: (c) 2021 by the authors. Licensee MDPI, Basel, Switzerland. This article is an open access article distributed under the terms and conditions of the Creative Commons Attribution (CC BY) license (https:/ / creativecommons.org/licenses/by/ $4.0 /)$.
Abstract: Background and Objectives: Vision impairments and related blindness are major public health problems. The prevalence of eye disease and barriers to optimal care markedly vary among different geographic areas. In the Abruzzo region (central Italy), an epidemiological surveillance on the state of ocular health in the population aged over 50 years was performed in 2019. Materials and Methods: Participants were sampled to be representative of the region's inhabitants. Data were collected through a telephone interview and an eye examination. Prevalence of cataract, glaucoma, retinopathy, and maculopathy was assessed. The Cohen's kappa (k) was used to measure the agreement between the presence of eye disease and awareness of the disease by the participants. Results: Overall, 983 people with a mean age of $66.0 \pm 9.5$ years were included in the study. The prevalence of cataracts, glaucoma, maculopathy, and retinopathy was $52.6 \%, 5.3 \%, 5.6 \%$, and $29.1 \%$, respectively. Among the total of the affected people, those aware of their condition were $21.8 \%(\mathrm{k}=0.12$, slight agreement) for cataract, $65.4 \%(\mathrm{k}=0.78$, substantial agreement $)$ for glaucoma, $7.1 \%(\mathrm{k}=0.10$, slight agreement) for maculopathy, and $0 \%$ for retinopathy $(\mathrm{k}=-0.004$, agreement lower than that expected by chance). Refractive defects were corrected in the vast majority of participants. Conclusions: In the Abruzzo region, about two thirds of citizens aged 50 years or over suffer from cataract, glaucoma, retinopathy, or maculopathy, which are recognized as leading causes of blindness. Many people with eye disease do not know they have it. These data can be used by clinicians and policymakers to undertake clinical, political, and social actions.

Keywords: population screening; eye disease; prevalence; awareness

\section{Introduction}

Vision impairments and related blindness are major public health concerns in middleaged and elderly adults worldwide, associated with diminished quality of life and increased risk of falls and death [1-3].

Available estimates suggest that 36 million people were blind, and 217 million people had moderate or severe vision impairment worldwide in 2015 [4].

The number of people affected by the common causes of vision loss has increased substantially as the population increases and ages. Simultaneously, the number of people with avoidable visual loss has increased. Cataract continues to cause most cases of blindness and moderate or severe vision impairment in adults aged 50 years and older, but also glaucoma, age-related macular degeneration, and retinopathy are major problems $[1,5]$.

Estimating the prevalence of vision impairment and patient needs are a fundamental basis of public health policies [5]. 
Based on the data, local healthcare systems can implement appropriate actions to address this largely preventable global problem and provide adequate eye care services.

Given these premises, a population-based epidemiological surveillance was conducted among individuals aged $\geq 50$ years in the Abruzzo region (Italy), aiming at estimating the prevalence of visual impairments (i.e., retinopathy, maculopathy, cataract, glaucoma) and people's characteristics and attitudes about eye health.

\section{Materials and Methods}

This was an epidemiological surveillance on the state of ocular health in the population aged over 50 years of the Abruzzo Region in 2019.

Participants were sampled to be representative of the region's inhabitants aged 50 years or older (2-stage sampling of randomly selected towns and cities of different sizes in the four provinces and representative distribution by gender and age classes). The sampling frame for selection was the list of persons living in the community, based on the local population registers held by the municipalities. After stratifying for gender and age, a sampling technique with probabilities proportionate to the size of each population stratum was used.

Data were collected through telephone interviews investigating socio-demographic and anamnestic information. The following data were collected: age, gender, school education, living status, working status, lifestyle information (physical activity, smoking habit, alcohol consumption, and daily exposition to ultraviolet rays), body mass index, and chronic diseases. Information about attention paid to the general and eye health and perceived health status was also collected.

Therefore, all participants underwent an eye examination through a mobile clinic. Refractive errors using a subjective and autorefractometer evaluation (auto refractometer AR-600 Nidek, Aichi, 443-0038, Japan), corneal assessment using slitlamp biomicroscopy, Amsler grid test, Ishihara test, cover-uncover test, and tonometric assessment were performed. In addition, in all patients a color fundus retinography was acquired using KOWA Nonmyd WX-3D retinal camera (Torrance, CA, USA).

Attention was paid to the following main eye diseases: cataract, glaucoma-related optic disc modifications, advanced age-related macular degeneration (AMD) (maculopathy), diabetic or hypertensive retinopathy, or other retinal vascular diseases (retinopathy). People diagnosed with these diseases were asked if they were aware of their condition.

The study was conducted in accordance with the Helsinki Declaration on Medical Research on Humans and with the Good Clinical Practice (GCP). The study did not require approval by the Ethics Committees, since it was based on the voluntary participation of people to an epidemiological screening campaign. Data collected were anonymous. Participants signed an informed consent for data protection according to European and national legislation.

\section{Statistical Analysis}

Descriptive data were summarized as the mean and standard deviation, median, and interquartile range or frequencies and proportions.

Characteristics of the study population were assessed overall and by awareness about eye diseases.

Groups were compared using the Student's $t$-test (continuous, normally distributed variables), Mann-Whitney U-test (continuous, not normally distributed variables), chisquare test or Fisher exact test (categorical variables), as appropriate.

The Cohen's kappa (k) was used to measure the agreement between the presence of eye disease and awareness of participants about the disease. A value of 1 implies perfect agreement and values less than 1 imply less than perfect agreement. Five levels of agreement have been identified based on k value: slight (0.01-0.20), fair (0.21-0.40), moderate (0.41-0.60), substantial (0.61-0.80), and almost perfect (0.81-1.00); negative $\mathrm{k}$ means that the agreement is less than that expected just by chance [6]. 
A $p$-value $<0.05$ was considered statistically significant. Statistical analyses were performed using the SAS program, version 9.4 (SAS Institute Inc., Cary, NC, USA).

\section{Results}

Overall, 983 people were included in the study. Participants' characteristics are summarized in Table 1.

Table 1. Characteristics of the study participants.

\begin{tabular}{|c|c|c|}
\hline & $n$ with Available Data & $\begin{array}{l}\text { Mean and Standard Deviation } \\
\text { or Frequency and Proportions }\end{array}$ \\
\hline$n$ & & 983 \\
\hline \multicolumn{3}{|l|}{ Socio-demographic characteristics } \\
\hline Men $(\%)$ & 983 & $451(45.9)$ \\
\hline Mean age (years) & 983 & $66.0 \pm 9.5$ \\
\hline Age in classes $(\%)$ : & 983 & \\
\hline$<65$ years & & $438(44.6)$ \\
\hline$\geq 65$ years & & $545(55.4)$ \\
\hline School education (\%): & 983 & \\
\hline$<5$ years & & $62(6.3)$ \\
\hline Primary school & & $271(27.6)$ \\
\hline Secondary school & & $312(31.7)$ \\
\hline High school & & $280(28.5)$ \\
\hline University degree & & $58(5.9)$ \\
\hline Civil status (\%) & 983 & \\
\hline Married/Partner & & 851 (86.6) \\
\hline Single/Divorced/Widow & & $132(13.4)$ \\
\hline Working status (\%) & 983 & \\
\hline Employed & & $230(23.4)$ \\
\hline Unemployed/retired & & $753(76.6)$ \\
\hline \multicolumn{3}{|l|}{ Lifestyle } \\
\hline Physical activity (\%) & 983 & \\
\hline Regular & & $95(9.7)$ \\
\hline Occasional & & $108(11.0)$ \\
\hline Never & & $780(79.3)$ \\
\hline Alcohol consumption (\%) & 983 & \\
\hline Regular & & $411(41.8)$ \\
\hline Occasional & & $107(10.9)$ \\
\hline Never & & $465(47.3)$ \\
\hline Smoking $(\%)$ & 983 & \\
\hline Yes & & $152(15.5)$ \\
\hline Ex & & $273(27.8)$ \\
\hline No & & $558(56.8)$ \\
\hline
\end{tabular}


Table 1. Cont.

\begin{tabular}{|c|c|c|}
\hline & $n$ with Available Data & $\begin{array}{l}\text { Mean and Standard Deviation } \\
\text { or Frequency and Proportions }\end{array}$ \\
\hline If yes, no. of cigarettes / day (\%) & 145 & \\
\hline$\leq 10$ & & $88(60.7)$ \\
\hline $11-20$ & & $48(33.1)$ \\
\hline$>20$ & & $9(6.2)$ \\
\hline If ex, date of cessation (\%) & 273 & \\
\hline$<10$ years & & $28(10.3)$ \\
\hline$>10$ years & & $56(20.5)$ \\
\hline$>20$ years & & $64(23.4)$ \\
\hline$>30$ years & & $77(28.2)$ \\
\hline$>40$ years & & $40(14.7)$ \\
\hline Unknown & & $8(2.9)$ \\
\hline $\begin{array}{c}\text { Daily exposition to ultraviolet } \\
\text { rays (\%) }\end{array}$ & 982 & \\
\hline None & & $4(0.4)$ \\
\hline Low (1-2 h/day) & & $230(23.4)$ \\
\hline Intermediate (2-3 h/day) & & $320(32.6)$ \\
\hline High (>3 h/day) & & $428(43.6)$ \\
\hline \multicolumn{3}{|l|}{ Clinical characteristics } \\
\hline Mean BMI $\left(\mathrm{kg} / \mathrm{m}^{2}\right)$ & 972 & $26.6 \pm 4.1$ \\
\hline BMI in classes $(\%)$ : & 972 & \\
\hline Underweight & & $11(1.1)$ \\
\hline Normal weight & & $346(35.7)$ \\
\hline Overweight & & $430(44.4)$ \\
\hline Obesity & & $181(18.7)$ \\
\hline Type 2 diabetes (\%) & 983 & $130(13.2)$ \\
\hline Hypertension (\%) & 983 & $411(41.8)$ \\
\hline Cardiovascular diseases (\%) & 983 & $119(12.1)$ \\
\hline Neurologic diseases (\%) & 983 & $26(2.6)$ \\
\hline Renal diseases (\%) & 983 & $50(5.1)$ \\
\hline Rheumatological diseases (\%) & 983 & $234(23.8)$ \\
\hline \multicolumn{3}{|l|}{ Attention to the own health status } \\
\hline $\begin{array}{c}\text { Do you check regularly your } \\
\text { health status? }(\%)\end{array}$ & 983 & \\
\hline Yes & & $767(78.0)$ \\
\hline $\begin{array}{l}\text { Sometimes/only in case of } \\
\text { problems }\end{array}$ & & $198(20.1)$ \\
\hline Never & & $18(1.8)$ \\
\hline
\end{tabular}


Table 1. Cont.

\begin{tabular}{ccc}
\hline & $n$ with Available Data & $\begin{array}{c}\text { Mean and Standard Deviation } \\
\text { or Frequency and Proportions }\end{array}$ \\
\hline $\begin{array}{c}\text { How would you define your } \\
\text { health? }(\%)\end{array}$ & 982 & \\
\hline Excellent & $109(11.1)$ \\
\hline Good & $724(73.7)$ \\
\hline Intermediate & $142(14.5)$ \\
\hline Poor & $7(0.7)$ \\
\hline Frequency of eye examination (\%) & $75(7.6)$ \\
\hline More than once a year & $305(31.0)$ \\
\hline Once a year & $219(22.3)$ \\
\hline Every 2 years & $384(39.1)$ \\
\hline Occasionally & \\
\hline
\end{tabular}

Mean age was $66.0 \pm 9.5$ years, men represented $45.9 \%$ of the sample, school education level was inferior to high school for $65.6 \%$ of participants, $20.7 \%$ performed physical activity, $15.5 \%$ were smokers, $41.8 \%$ consumed alcohol regularly, $63.1 \%$ were overweight or obese, and $41.8 \%$ had hypertension. Although unhealthy lifestyle and comorbidities were documented in many patients, $78.0 \%$ declared regularly checking their own health status and $60.9 \%$ declared to attend an eye examination at least every 2 years. Good/excellent health was reported by $84.8 \%$ of participants.

In eye examination, astigmatism was identified as the most frequent refractive defect, while daltonism and strabismus were seldom detected (Table 2).

Table 2. General eye health status and prevalence of eye diseases.

\begin{tabular}{ccc}
\hline Eye Examination & $n$ with Available Data & $\begin{array}{c}\text { Mean and Standard Deviation } \\
\text { or Frequency and Proportions }\end{array}$ \\
\hline$n$ & 983 \\
\hline $\begin{array}{c}\text { See well with or without glasses } \\
(20 / 20 \text { snellen visual acuity) }\end{array}$ & 983 & $550(56.0)$ \\
\hline $\begin{array}{c}\text { Low vision (best corrected or } \\
\text { uncorrected })\end{array}$ & 983 & $32(3.3)$ \\
\hline Refractive error $(\%)$ & 983 & $96(9.8)$ \\
\hline Myopia (>-0.25 sph) & $313(31.8)$ \\
\hline Hyperopia (>+0.25 sph) & $435(44.3)$ \\
\hline Astigmatism $( \pm 0.25$ cyl) & $139(14.1)$ \\
\hline None & 965 & $63(6.5)$ \\
\hline AMSLER grid: presence of $(\%)$ & $2(0.2)$ \\
\hline Metamorphopsia & $2(0.2)$ \\
\hline Scotoma & $898(93.1)$ \\
\hline Scotoma and metamorphopsia &
\end{tabular}


Table 2. Cont.

\begin{tabular}{|c|c|c|}
\hline Eye Examination & $n$ with Available Data & $\begin{array}{l}\text { Mean and Standard Deviation } \\
\text { or Frequency and Proportions }\end{array}$ \\
\hline Discromatopsia (Ishihara test) (\%) & 971 & $38(3.9)$ \\
\hline $\begin{array}{c}\text { Strabismus } \\
\text { (Cover-uncover test) }(\%)\end{array}$ & 954 & $46(4.8)$ \\
\hline Corneal disorder $(\%)$ & 919 & $5(0.5)$ \\
\hline Mean tone $(\mathrm{mmHg})$ & 977 & $14.7 \pm 3.2$ \\
\hline Cataract $(\%)$ & 916 & $482(52.6)$ \\
\hline $\begin{array}{l}\text { History of surgical treatment for } \\
\text { cataract }(\%)\end{array}$ & 186 & $97(52.2)$ \\
\hline $\begin{array}{l}\text { Satisfaction with surgical } \\
\text { treatment for cataract (\%) }\end{array}$ & 97 & \\
\hline Very satisfied & & $9(9.3)$ \\
\hline Satisfied & & $83(85.6)$ \\
\hline Partly satisfied & & $5(5.2)$ \\
\hline $\begin{array}{c}\text { Glaucoma-related optic nerve } \\
\text { head alterations (\%) }\end{array}$ & 981 & $52(5.3)$ \\
\hline $\begin{array}{c}\text { Advanced Age-Related Macular } \\
\text { Degeneration } \\
\text { (AMD)/maculopathy (\%) }\end{array}$ & 480 & $27(5.6)$ \\
\hline $\begin{array}{l}\text { Vascular eye diseases (diabetic } \\
\text { retinopathy, hypertensive } \\
\text { retinopathy, occlusive } \\
\text { vasculopathies)/retinopathy (\%) }\end{array}$ & 474 & $138(29.1)$ \\
\hline
\end{tabular}

In terms of primary study objective, the prevalence of cataract, glaucoma, maculopathy, and retinopathy was 52.6\% 5.3\%, 5.6\%, and 29.1\%, respectively (Table 2 and Figure 1).

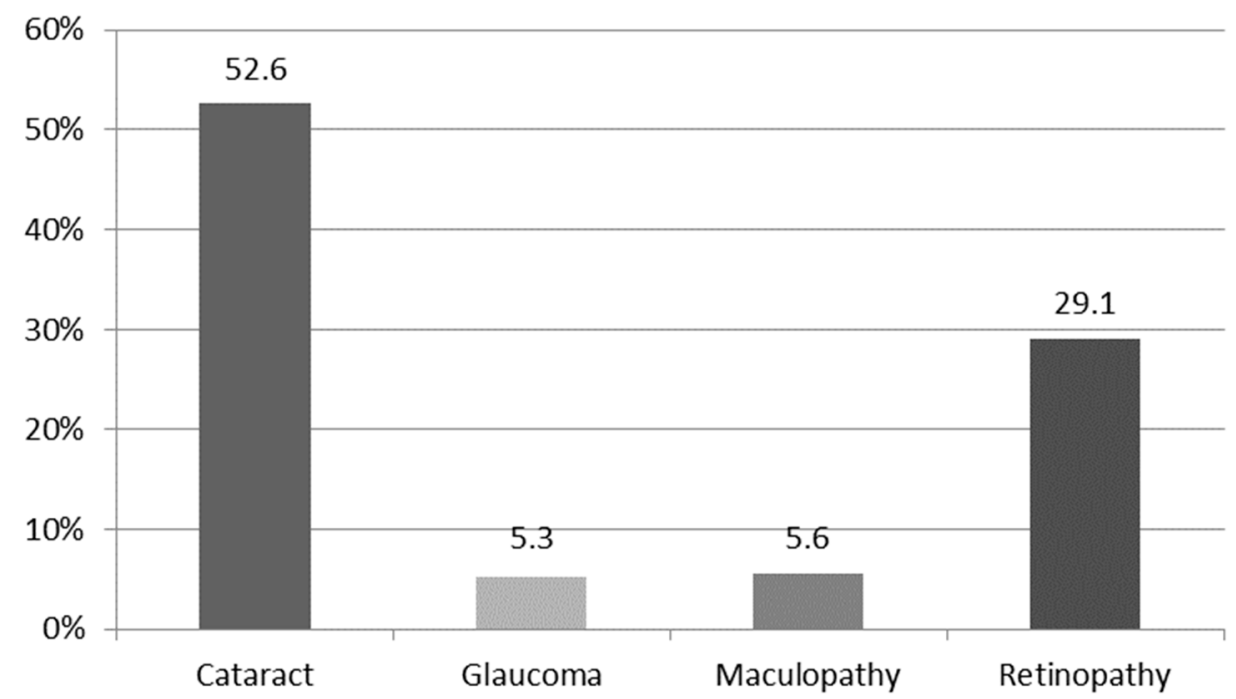

Figure 1. Prevalence of eye diseases among the general population aged $\geq 50$ years.

Among the total of affected people, those aware of their condition were $21.8 \%(\mathrm{k}=0.12$, slight agreement) for cataract, $65.4 \%$ ( $k=0.78$, substantial agreement) for glaucoma, $7.1 \%$ $(\mathrm{k}=0.10$, slight agreement) for maculopathy, and $0 \%$ for retinopathy $(\mathrm{k}=-0.004$, agreement lower than that expected by chance) (Figure 2). 


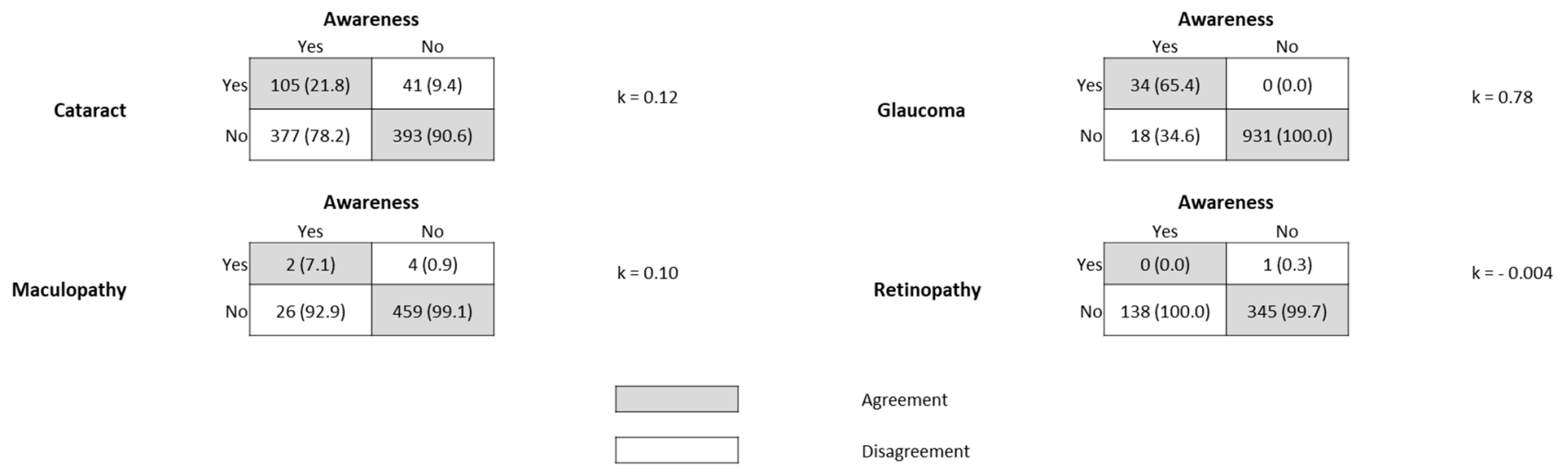

Figure 2. People aware about their eye disease. Rows indicate the presence/absence of eye disease whilst the columns indicate the awareness of participants about the disease.

Comparisons between characteristics of people aware or not aware was feasible for cataract only (for the other diseases, prevalence was low, and sub-samples stratified by agreement insufficient). Compared to people not aware about their cataract, aware people were older (73 vs. 67 years), were more often women than men ( $60 \%$ vs. $40 \%)$, were less likely to be married $(23.8 \%$ vs. $9.3 \%)$ and were more likely to have a low school education (58.1 vs. $33.9 \%$ ) (Table 3).

Table 3. Subgroup of patients with cataract $(n=482)$ and their characteristics by awareness about their cataract.

\begin{tabular}{|c|c|c|c|}
\hline & Aware & Not Aware & $p$-Value * \\
\hline$n$ & 105 & 377 & \\
\hline \multicolumn{4}{|c|}{ Socio-demographic characteristics } \\
\hline Men $(\%)$ & $42(40.0)$ & $172(45.6)$ & 0.30 \\
\hline Mean age (years) & $73.0 \pm 6.8$ & $67.0 \pm 8.4$ & $<0.0001$ \\
\hline \multicolumn{4}{|l|}{ School education (\%) } \\
\hline$<$ Secondary school & $61(58.1)$ & $128(33.9)$ & 0.0005 \\
\hline$\geq$ Secondary school & $44(41.9)$ & $249(66.1)$ & \\
\hline \multicolumn{4}{|l|}{ Civil status: } \\
\hline Married/Partner & $78(74.3)$ & $333(88.3)$ & 0.0003 \\
\hline Single/Divorced/Widow & $27(25.7)$ & $44(11.7)$ & \\
\hline \multicolumn{4}{|l|}{ Working status (\%) } \\
\hline Retired & $88(83.8)$ & $245(65.0)$ & $<0.0001$ \\
\hline Employed & $17(16.2)$ & $132(35.0)$ & \\
\hline \multicolumn{4}{|l|}{ Lifestyle } \\
\hline \multicolumn{4}{|l|}{ Physical activity (\%) } \\
\hline Regular & $3(2.9)$ & $28(7.4)$ & 0.16 \\
\hline Sometimes & $9(8.6)$ & $42(11.1)$ & \\
\hline Never & $93(88.6)$ & $307(81.4)$ & \\
\hline \multicolumn{4}{|l|}{ Alcohol consumption (\%) } \\
\hline Regular & $37(35.2)$ & $160(42.4)$ & 0.15 \\
\hline Sometimes & $9(8.6)$ & 45 (11.9) & \\
\hline Never & $59(56.2)$ & $172(45.6)$ & \\
\hline
\end{tabular}


Table 3. Cont.

\begin{tabular}{|c|c|c|c|}
\hline & Aware & Not Aware & $p$-Value * \\
\hline \multicolumn{4}{|l|}{ Smoking $(\%)$} \\
\hline Yes & $10(9.5)$ & $62(16.4)$ & 0.18 \\
\hline Ex & $29(27.6)$ & $106(28.1)$ & \\
\hline No & $66(62.9)$ & $209(55.4)$ & \\
\hline \multicolumn{4}{|l|}{ Clinical characteristics } \\
\hline Mean BMI $\left(\mathrm{kg} / \mathrm{m}^{2}\right)$ & $27.1 \pm 4.7$ & $26.7 \pm 4.0$ & 0.95 \\
\hline \multicolumn{4}{|l|}{ BMI in classes $(\%)$ : } \\
\hline Underweight & $0(0.0)$ & $4(1.1)$ & 0.78 \\
\hline Normal weight & $37(36.3)$ & $123(33.2)$ & \\
\hline Overweight & $43(42.2)$ & $170(45.8)$ & \\
\hline Obesity & $22(21.6)$ & $74(19.9)$ & \\
\hline Type 2 diabetes (\%) & $16(15.2)$ & $60(15.9)$ & 0.87 \\
\hline Hypertension (\%) & $62(59.0)$ & $158(41.9)$ & 0.002 \\
\hline Cardiovascular diseases (\%) & $19(18.1)$ & 45 (11.9) & 0.10 \\
\hline Neurologic diseases (\%) & $2(1.9)$ & $11(2.9)$ & 0.74 \\
\hline Renal diseases (\%) & $8(7.6)$ & $25(6.6)$ & 0.72 \\
\hline Rheumatological diseases (\%) & $27(25.7)$ & $106(28.1)$ & 0.63 \\
\hline \multicolumn{4}{|l|}{ Attention to the own health status } \\
\hline \multicolumn{4}{|c|}{ Do you check regularly your health status? (\%) } \\
\hline Yes & $85(81.0)$ & $299(79.3)$ & 0.37 \\
\hline Sometimes/only in case of problem & $20(19.0)$ & $71(18.8)$ & \\
\hline Never & $0(0.0)$ & $7(1.9)$ & \\
\hline \multicolumn{4}{|l|}{ How would you define your health? (\%) } \\
\hline Excellent & $2(1.9)$ & $34(9.0)$ & 0.003 \\
\hline Good & $76(72.4)$ & $286(76.1)$ & \\
\hline Intermediate & $26(24.8)$ & $55(14.6)$ & \\
\hline Poor & $1(1.0)$ & $1(0.3)$ & \\
\hline \multicolumn{4}{|l|}{ Frequency of eye examination (\%) } \\
\hline More than once a year & $9(8.6)$ & $26(6.9)$ & 0.21 \\
\hline Once a year & $39(37.1)$ & $104(27.6)$ & \\
\hline Every 2 years & $22(21.0)$ & $91(24.1)$ & \\
\hline Occasionally & $35(33.3)$ & $156(41.4)$ & \\
\hline \multicolumn{4}{|l|}{ Other eye disease } \\
\hline Glaucoma (\%) & $8(7.6)$ & $8(2.1)$ & 0.01 \\
\hline Maculopathy (\%) & $3(2.9)$ & $5(1.3)$ & 0.38 \\
\hline Retinopathy (\%) & $1(1.0)$ & $0(0.0)$ & 0.22 \\
\hline
\end{tabular}

* Student's $t$-test, Mann-Whitney U-test, chi-square test or Fisher exact test, as appropriate. Statistically significant $p$-value $(<0.05)$ are in bold text. 


\section{Discussion}

\subsection{Main Findings}

Low vision affects many people aged over 50 years. However, in our study most individuals could see well with best corrected or uncorrected refractive errors, and only $3.3 \%$ had severe visual impairment. Cataract was frequent and affected half of the population, while retinopathy was found in almost one third. Maculopathy and glaucoma affected about 1 out of 200 people. While people reported a good compliance to regular checks of their general and eye health, this study suggested an important gap between the presence/absence of eye disease and people's awareness about the disease. The majority of people with glaucoma (65.5\%) knew they had the disease. The level of awareness substantially decreased for the other eye diseases: only $21.8 \%$ of people with cataract and $7.1 \%$ with maculopathy knew they had the disease, while nobody of 138 affected people was aware about their retinopathy.

\subsection{Comparisons with Existing Knowledge}

Causes of visual impairments were measured in many countries and settings, documenting that prevalence is influenced by ethnicity and healthcare resource availability [7-10]. Recently, an updated review from the Global Vision Database identified 288 studies of 3,983,541 participants from 98 countries. It documented that cataract and uncorrected refractive error combined contributed to $55 \%$ of blindness and $77 \%$ of vision impairment in adults aged 50 years and older in 2015 [5]. World regions varied markedly in the causes of blindness and vision impairment in this age group, with a low prevalence of cataract ( $<22 \%$ for blindness and $14.1-15.9 \%$ for vision impairment) and a high prevalence of age-related macular degeneration ( $>14 \%$ of blindness) as causes in the high-income subregions [5].

In another Italian population-based study, the main cause of eye impairment in people aged 40 years and over was unoperated cataract (34.8\%), followed by glaucoma $(21.7 \%)$, degenerative myopia (13.0\%), and maculopathy (8.7\%) [11]. Furthermore, compared to our study population, in a study conducted in the north-east of Italy and involving 1162 people aged 60 years or over, prevalence of maculopathy was markedly higher $(62.7 \%)$, due to the inclusion of all stages of AMD and the different ages of the patients [12].

Poor health awareness of these conditions and their complications causes a delay in seeking medical care and precludes the chance of early intervention and prevention [5]. Therefore, raising public awareness of ocular diseases plays a significant role in the early diagnosis and treatment of such conditions, thus reducing the burden of visual impairment. To date, variable results have been reported about the level of awareness of common ocular diseases worldwide [13-18]. For example, in developed countries such as Canada, the level of awareness of ocular diseases was reported at $69 \%$ for cataract and $41 \%$ for glaucoma [19]. In India, knowledge about ocular diseases was poor both in urban and rural areas [20,21]. For instance, in a report from southern India, the majority of patients $(90 \%)$ with glaucoma were not aware of the condition and its complications [22]. In another study in India, a very poor awareness of glaucoma (3.2\%) and diabetic retinopathy (27\%) was also reported [14].

\subsection{Implications for Research and Clinical Practice}

Vision impairment is a key issue for people's quality of life and the public health of different countries. The burden of uncorrected refractive error contributes to almost half of the moderate and severe vision impairment burden, especially in low-income countries [22]. In high-income countries, effective diabetic retinopathy screening programs are in place. However, in Italy a standardized national diabetic eye screening program does not exist yet. On the other hand, due to their asymptomatic and/or monocular nature at early stages, in many settings glaucoma and maculopathy are not arrested or mitigated by timely interventions, although they are leading causes of blindness.

Efforts to identify organizational and cultural barriers should be made to improve access, equity, and efficacy of eye care to prevent blindness. Local periodical surveil- 
lance or annual patient recall could be effective strategies to identify priority and address actions [5,22].

Moreover, telemedicine in ocular diagnosis needs to be implemented in primary settings worldwide.

\subsection{Strengths and Limitations}

The study has strengths and limitations. The major strength is that, to the best of our knowledge, this is the first evaluation of the awareness of eye diseases in an Italian population. Furthermore, the study population is quite representative of many central and southern Italian communities.

On the other hand, the major limitation was the small number of subgroups examined to assess the factors associated with the awareness of having glaucoma, maculopathy, or retinopathy. Nevertheless, factors associated with the knowledge of having cataract suggest the role of demographic and socio-economic characteristics as correlates of awareness.

Furthermore, given the mobile clinic setting, we could not diagnose all eye diseases (e.g., hereditary retinal diseases) or classify the stages of the diseases (e.g., strabism, glaucoma, AMD, other retinal diseases) but just detect their presence or absence. This was due to the lack of specific necessary exams or instruments, such as optical coherence tomography, electroretinogram tests, and genetic tests.

\section{Conclusions}

This regional epidemiological study provided useful information to clinicians and policymakers, highlighting that in this area, the refractive defect is corrected in the large majority of people aged 50 years or over. However, about two thirds of citizens in this age class suffer from cataract, glaucoma, retinopathy, or maculopathy, which are recognized as leading causes of blindness. Many people with eye disease do not know they have it. These data can be used to improve access to care and promote information campaigns.

Author Contributions: Conceptualization, L.M.; and F.C.; Formal Analysis, L.C. (Loredana Cerbara); Investigation, A.M., F.P. and L.C. (Luca Cerino); Writing-Original Draft Preparation, R.D.; WritingReview and Editing, L.T.; Supervision, L.M. All authors have read and agreed to the published version of the manuscript.

Funding: This research received no external funding.

Institutional Review Board Statement: The study was conducted in accordance with according to the guidelines of the Declaration of Helsinki. Ethical review and approval were waived for this study, since it was based on the voluntary participation of people to an epidemiological screening campaign.

Informed Consent Statement: Data collected were anonymous. Participants signed an informed consent for data protection according to European and national legislation.

Data Availability Statement: The study database is not publicly available. It could be provided upon reasonable request to the authors.

Conflicts of Interest: None of the following authors have any proprietary interests or conflicts of interest related to this submission.

\section{References}

1. Sabanayagam, C.; Cheng, C.Y. Global causes of vision loss in 2015: Are we on track to achieve the Vision 2020 target? Lancet Glob. Health 2017, 5, e1164-e1165. [CrossRef]

2. McCarty, C.A.; Nanjan, M.B.; Taylor, H.R. Vision impairment predicts 5 years mortality. Br. J. Ophthalmol 2001, 85, 322-326. [CrossRef]

3. Ramrattan, R.S.; Wolfs, R.C.; Panda-Jonas, S.; Jonas, J.B.; Bakker, D.; Pols, H.A.; Hofman, A.; de Jong, P.T. Prevalence and causes of visual field loss in the elderly and associations with impairment in daily functioning: The Rotterdam Study. Arch. Ophthalmol. 2001, 119, 1788-1794. [CrossRef]

4. Bourne, R.R.; Flaxman, S.R.; Braithwaite, T.; Cicinelli, M.V.; Das, A.; Jonas, J.B.; Keeffe, J.; Kempen, J.H.; Leasher, J.; Limburg, H.; et al. Magnitude, temporal trends, and projections of the global prevalence of blindness and distance and near vision impairment: A systematic review and meta-analysis. Lancet Glob. Health 2017, 5, e888-e897. [CrossRef] 
5. Flaxman, S.R.; Bourne, R.R.; Resnikoff, S.; Ackland, P.; Braithwaite, T.; Cicinelli, M.V.; Das, A.; Jonas, J.B.; Keeffe, J.; Kempen, J.H.; et al. Global causes of blindness and distance vision impairment 1990-2020: A systematic review and meta-analysis. Lancet Glob. Health 2017, 5, e1221-e1234. [CrossRef]

6. Landis, J.; Koch, R.G.G. The Measurement of Observer Agreement for Categorical Data. Biometrics 1977, 33, 159-174. Available online: www.jstor.org/stable/2529310 (accessed on 12 June 2021). [CrossRef] [PubMed]

7. Congdon, N.; O'Colmain, B.; Klaver, C.C.; Klein, R.; Muñoz, B.; Friedman, D.S.; Kempen, J.; Taylor, H.R.; Mitchell, P.; Eye Diseases Prevalence Research Group; et al. Causes and prevalence of visual impairment among adults in the United States. Arch. Ophthalmol. 2004, 122, 477-485.

8. Furtado, J.M.; Lansingh, V.C.; Carter, M.J.; Milanese, M.F.; Peña, B.N.; Ghersi, H.A.; Bote, P.L.; Nano, M.E.; Silva, J.C. Causes of blindness and visual impairment in Latin America. Surv. Ophthalmol. 2012, 57, 149-177. [CrossRef] [PubMed]

9. Xu, L.; Wang, Y.; Li, Y.; Wang, Y.; Cui, T.; Li, J.; Jonas, J.B. Causes of blindness and visual impairment in urban and rural areas in Beijing: The Beijing Eye Study. Ophthalmology 2006, 113, 1134.e1-1134.e11. [CrossRef]

10. Taylor, H.R.; Keeffe, J.E.; Vu, H.T.; Wang, J.J.; Rochtchina, E.; Mitchell, P.; Pezzullo, M.L. Vision loss in Australia. Med. J. Aust. 2005, 182, 565-568. [CrossRef]

11. Cedrone, C.; Nucci, C.; Scuderi, G.; Ricci, F.; Cerulli, A.; Culasso, F. Prevalence of blindness and low vision in an Italian population: A comparison with other European studies. Eye (Lond.) 2006, 20, 661-667. [CrossRef]

12. Piermarocchi, S.; Segato, T.; Scopa, P.; Masetto, M.; Ceca, S.; Cavarzeran, F.; Peto, T.; PAMDI Study Group. The prevalence of age-related macular degeneration in Italy (PAMDI) study: Report 1. Ophthalmic Epidemiol. 2011, 18, 129-136. [CrossRef]

13. Haddad, M.F.; Bakkar, M.M.; Abdo, N. Public awareness of common eye diseases in Jordan. BMC Ophthalmol. 2017, $17,177$. [CrossRef]

14. Dandona, R.; Dandona, L.; John, R.K.; McCarty, C.A.; Rao, G.N. Awareness of eye diseases in an urban population in southern India. Bull. World Health Organ. 2001, 79, 96-102.

15. Shrestha, M.K.; Guo, C.W.; Maharjan, N.; Gurung, R.; Ruit, S. Health literacy of common ocular diseases in Nepal. BMC Ophthalmol. 2014, 14, 2. [CrossRef] [PubMed]

16. Attebo, K.; Mitchell, P.; Cumming, R.; BMath, W.S. Knowledge and beliefs about common eye diseases. Aust. N. Z. J. Ophthalmol. 1997, 25, 283-287. [CrossRef]

17. Chew, Y.K.; Reddy, S.C.; Karina, R. Awareness and knowledge of common eye diseases among the academic staff (non-medical faculties) of University of Malaya. Med. J. Malays. 2004, 59, 305-311.

18. Noertjojo, K.; Maberley, D.; Bassett, K.; Courtright, P. Awareness of eye diseases and risk factors: Identifying needs for health education and promotion in Canada. Can. J. Ophthalmol. 2006, 41, 617-623. [CrossRef]

19. Sathyamangalam, R.V.; Paul, P.G.; George, R.; Baskaran, M.; Hemamalini, A.; Madan, R.V.; Augustian, J.; Prema, R.; Lingam, V. Determinants of glaucoma awareness and knowledge in urban Chennai. Indian J. Ophthalmol. 2009, 57, 355-360. [PubMed]

20. Vijaya, L.; George, R.; Arvind, H.; Baskaran, M.; Ramesh, S.V.; Raju, P.; Kumaramanickavel, G.; McCarty, C. Prevalence of primary angle-closure disease in an urban south Indian population and comparison with a rural population. The Chennai Glaucoma Study. Ophthalmology 2008, 115, 655-660.e1. [CrossRef] [PubMed]

21. Vijaya, L.; George, R.; Baskaran, M.; Arvind, H.; Raju, P.; Ramesh, S.V.; Kumaramanickavel, G.; McCarty, C. Prevalence of primary open-angle glaucoma in an urban south Indian population and comparison with a rural population. The Chennai Glaucoma Study. Ophthalmology 2008, 115, 648-654.e1. [CrossRef] [PubMed]

22. Bourne, R.R.; Jonas, J.B.; Bron, A.M.; Cicinelli, M.V.; Das, A.; Flaxman, S.R.; Friedman, D.S.; Keeffe, J.E.; Kempen, J.H.; Leasher, J.; et al. Prevalence and causes of vision loss in high-income countries and in Eastern and Central Europe in 2015: Magnitude, temporal trends and projections. Br. J. Ophthalmol. 2018, 102, 575-585. [CrossRef] [PubMed] 